\title{
Canal aberto
}

1 gestão empresarial está se tornando cada vez mais complexa. 1 Além de competitividade e capacidade de inovação, o con4 texto de negócios exige das organizações um posicionamento claro acerca de temas como diversidade, direitos humanos, impactos ambientais, saúde e bem-estar dos colaboradores e da comunidade. Algumas questões-chave devem ser respondidas. Como conciliar valores universais com os processos empresariais? Como desenvolver lideranças e profissionais focados na sustentabilidade econômica, social e ambiental? Um caso ocorrido na Natura mostra como, a partir da ação de uma consumidora, a empresa equacionou essas questões e incorporou o conceito de responsabilidade social a seu dia-a-dia.

por Sonia Loureiro CETS/FGV-EAESP

Ao examinar o catálogo de produtos da $N$ atura Cosméticos, empresa da qual é fiel consumidora, a bióloga Ilka Fioravante Altoé surpreendeu-se ao ver que o lançamento preparado para o Dia das Mães de 2001 - um estojo de chás em madeira - parecia ter sido feito de imbuia, uma espécie vegetal ameaçada de extinção.
Indignada, Ilka telefonou para São Paulo e falou com o serviço de atendimento ao consumidor da $\mathrm{N}$ atura. Apresentou sua dúvida e exigiu que a empresa apresentasse, ao menos, o certificado de origem da madeira, documento legal emitido pelo Ibama. Ilka também argumentou que uma empresa como a $\mathrm{N}$ atura, que ma- 
nifesta publicamente seu compromisso com a conservação do meio ambiente, não poderia dar um mau exemplo como esse. Sem resposta imediata, ela contudo obteve o compromisso da atendente de que o caso seria encaminhado às áreas responsáveis. Ilka e sua família decidiram parar de utilizar os produtos da empresa até receber uma justificativa viável para o fato.

o que poderia ser visto como exagerado zelo de uma consumidora movimentou várias áreas da $\mathrm{N}$ atura. Do serviço de atendimento ao consumidor, o caso passou para as mãos do Comitê de Crise, formado pelo presidente de 0 perações, pelo vice-presidente de Inovação, pelo diretor de Assuntos Corporativos e pelo gerente do Segmento Saúde. De fato, a madeira era mesmo a imbuia, e a empresa fornecedora das caixas de chá tinha o certificado do Ibama. Mas quem poderia garantir à $\mathrm{N}$ atura que a extração fora feita de forma sustentável, como exige o compromisso expresso pela empresa? A N atura decidiu, então, recorrer à Imaflora, uma ONG, parceira responsável pela certificação de ativos utilizados em seus produtos.

A N atura recebeu o laudo da Imaflora, que apontou algumas inconsistências no processo de extração da madeira dos estojos de chá, pois não havia um plano de manejo que garantisse os princípios de sustentabilidade. Diante disso, a empresa decidiu assumir a fal ha e realizar ações reparatórias, tornando públicas as iniciativas.

Errar é possível, concluíram as lideranças da companhia, principalmente em negócios tão complexos quanto os que envolvem uma empresa de cosméticos do porte da Natura, seus fornecedores e as relações que se estabelecem a longa distância. Ocultar o erro, porém, seria inadmissível, especialmente para uma organização pautada pela ética e transparência, que dirige todas as ações de gestão - administrativa, econômica, social e ambiental - para a responsabilidade social corporativa.

Em novo tel efonema da $\mathrm{N}$ atura, Ilka ficou sabendo quais seriam as medidas reparatórias: o plantio de dez hectares de mata nativa no Espaço $\mathrm{N}$ atura em Cajamar, em quantidade duas vezes maior do que a necessária para produzir os estojos de chá, e a destinação dos recursos obtidos com a venda dos estojos para uma organização ambientalista que tivesse, em suas bases de atuação, o trabalho de recuperação de florestas, a conservação da imbuia e um caráter educativo. Satisfeita com as providências adotadas, Ilka decidiu voltar a usar os produtos da Natura.

Algum tempo depois, em fevereiro de 2002, Ilka e sua filha Aline atenderam ao convite da empresa e participaram, em São Paulo, do plantio simbólico de uma

0 poder do consumidor. Entristecida por não ter obtido uma resposta concreta da $N$ atura e sentindo falta dos produtos que ela e sua família utilizavam, Ilka finalmente recebeu um tel efonema da empresa. 0 interlocutor da Natura admitiu que a madeira era a imbuia e garantiu que, mesmo de posse do certificado do Ibama, a empresa iria investigar minuciosamente o processo extrativo. Recompensada, a bióloga convenceu-se de que estava certa em ter alertado a Natura, lembrando que não foram poucos os conselhos de amigos para que desistisse da iniciativa. muda de imbuia no Espaço Natura. "Foi emocionante ver o poder que nós, consumidores, temos em nossas mãos", afirmou a bióloga, na época. "A transparência e a honestidade da $\mathrm{N}$ atura também me surpreenderam e me deram a certeza de que, com coragem e decisão, podemos garantir a existência das futuras gerações".

Fomentando a cultura corporativa. 0 incidente ocorrido com a $\mathrm{N}$ atura passou a ser chamado de "o caso dos estojos de chá". Ele denota o que o envolvimento 
efetivo das partes interessadas pode trazer de positivo para os processos da empresa. Com efeito, avanços significativos na revisão dos processos internos das corporações podem ser obtidos por empresas que estão em sintonia com as questões de interesse da sociedade, que promovem o diálogo e estão preparadas para incorporar seus interesses legítimos nos planos de negócio.

Fatos como esse exigem que a empresa tome decisões radicais, capazes de distinguir o discurso da prática e de fomentar uma cultura corporativa voltada para a responsabilidade social. Certa disso, a $N$ atura desen volveu uma campanha de comunicação dirigida a colaboradores, promotoras de vendas, consultoras - revendedoras -, consumidores finais e formadores de opinião. Para isso, utilizou seus veí-

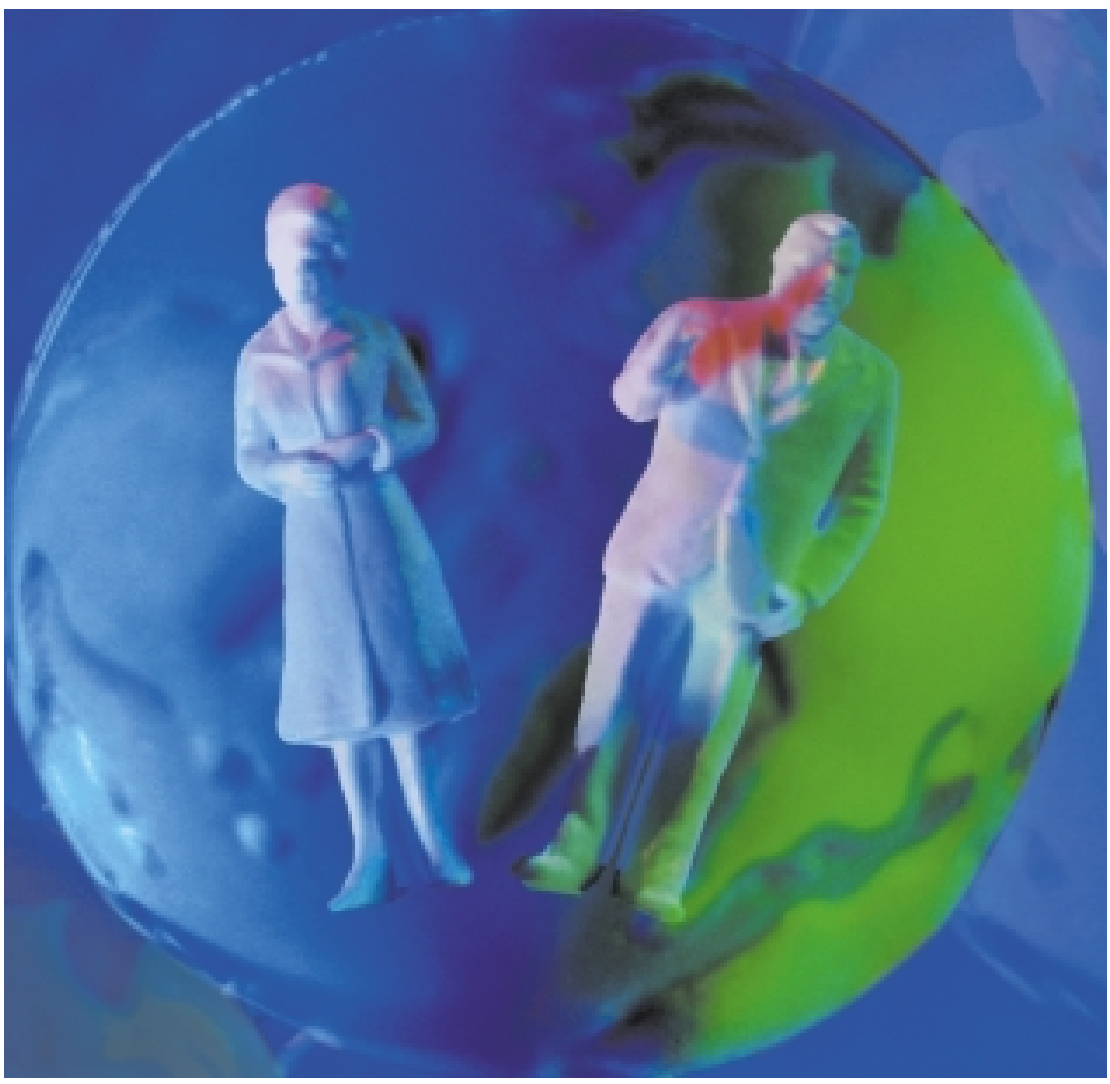
culos de comunicação, internos e externos, e acionou sua área de relações com a imprensa.

Para escolher as ONGs às quais seria destinada a verba da ação reparatória, a empresa pediu sugestões a colaboradores e consumidores por meio da Internet e do site www.natura.net. A história dos estojos de chá também foi publicada no Relatório Anual de Responsabilidade Corporativa e na edição especial do Ser $N$ atura Colaborador sobre o Balanço Social. 0 caso e seus desdobramentos foram objeto de reportagem na revista Exame, da Editora Abril, e de matéria de capa do jornal Gazeta M ercantil. Hoje, os funcionários e executivos da $\mathrm{N}$ atura conhecem Ilka e sabem o que el a representa para a empresa. A imbuia tornou-se um dos marcos no programa de visitas ao Espaço $\mathrm{N}$ atura.

As faces da responsabilidade social. 0 caso dos estojos de chá demonstra que é viável aplicar valores e princípios a ações cotidianas. E mais: mostra que é possível colher bons resultados para o negócio quando a

agenda econômico-financeira não se sobrepõe à agenda social e ambiental.

Também é importante destacar que todo o processo se iniciou no ato de consumo consciente, que levou em consideração o impacto da compra sobre o meio ambiente. Esse exemplo é significativo do fato do desenvolvimento sustentável estar crescendo como parâmetro de escolha no comportamento do consumidor também no Brasil. Dados de pesquisa do Instituto Ethos sobre as expectativas do consumidor com relação ao comportamento social das organizações indicam que $63 \%$ julgam as empresas com base em sua responsabilidade social, $66 \%$ consideram que as grandes corporações devem responder pelo desenvolvimento da sociedade e $35 \%$ julgam ser esta sua principal responsabilidade. Embora apenas $22 \%$ dos consumidores tenham declarado que recompensaram ou puniram empresas pelo menos uma vez no último ano, em função de seu comportamento de responsabilidade social, a expressiva diferença entre desejo (63\%) e ação (22\%) já sugere mudanças nessa direção. 
Sustentabilidade. Em realidade, o caso do estojo de chá veio ilustrar e reafirmar o compromisso da $\mathrm{N}$ atura com a responsabilidade social corporativa. Foi esse compromisso que levou a empresa a investir no desenvolvimento sustentável, pesquisando e buscando novas formas de utilizar a rica biodiversidade brasileira em seus produtos. Com o propósito de vincular produtos a conceitos e valores, em 2000 foi lançada a Linha $\mathrm{N}$ atura Ekos, que utiliza ativos extraídos da flora brasileira.

Compõe essa iniciativa o Programa de Certificação de Ativos, desenvolvido para garantir que os insumos vegetais sejam extraídos de forma ambientalmente correta e social mente justa. Trata-se de um instrumento que promove o manejo florestal sustentável por meio de certificação das áreas de plantações e matas nativas baseada nos critérios do Forest Stewardship Council.
Avaliação das práticas. Para dar visibilidade a suas ações, a Natura adota os indicadores e o modelo de balanço social da Global Reporting Iniciative - GRI -, instituição de abrangência e credibilidade mundial, na elaboração e publicação do Relatório Anual de Responsabilidade Corporativa, atualmente na segunda edição. Junto ao Guia de Elaboração de Relatório Anual de Responsabilidade Social Empresarial do Instituto Ethos, os indicadores da GRI são utilizados para identificar 0 atual estágio da empresa em suas iniciativas de responsabilidade social, corrigir rotas e estabelecer metas de melhorias. A Natura utiliza, ainda, os Indicadores Ethos de Responsabilidade Social Empresarial para avaliar internamente suas práticas. Em 2001, pelo segundo ano consecutivo, a pesquisa dos Indicadores Ethos mostrou que a $N$ atura faz parte do grupo de empresas brasileiras associadas que são referência em responsabilidade social.

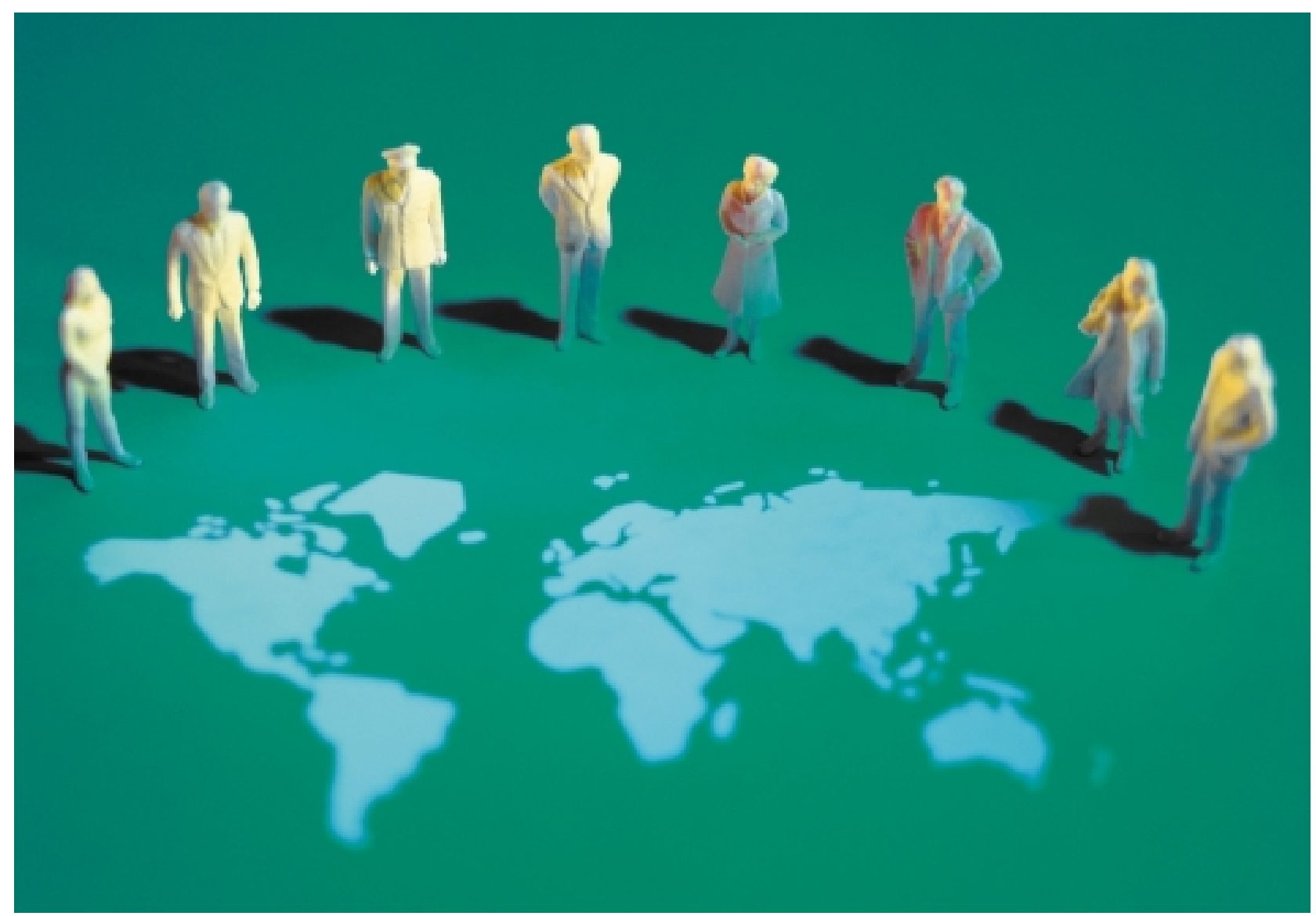


Como se depreende das pesquisas do Instituto Ethos, além da $\mathrm{N}$ atura, existem outras empresas brasilei ras comprometidas com o desenvolvimento sustentável. À medida que essas organizações avançam na compreensão dos conceitos da responsabilidade social corporativa como parte da estratégia empresarial, cresce a busca por modelos de gestão que permitem incorporar práticas socialmente responsáveis ao plano de negócios. Não existe um sistema único de gestão da responsabilidade social corporativa, e sim processos de aprimoramento das técnicas de gestão preexistentes na administração de empresas, tomando por base as boas práticas de organizações mais experientes no enfrentamento das novas demandas da sociedade. Algumas ferramentas de gestão podem ser utilizadas para viabilizar a aval iação, o planejamento e o monitoramento das práticas empresariais e seu alinhamento com as políticas que se deseja adotar.
0 caso examinado mostra, por fim, que é preciso que as empresas assumam seus compromissos éticos de forma clara e transparente e aproveitem incidentes

\section{As empresas devem assumir seus} compromissos éticos de forma clara e transparente, aproveitando incidentes e crises para disseminar a coerência entre seus valores e suas práticas.

e crises para disseminar, entre os diversos públicos de interesse, a coerência entre seus valores e crenças e suas práticas, conquistando, desse modo, o fortalecimento de sua imagem e uma maior qualidade em suas diversas relações.

\section{Ciclo virtuoso}

A atitude da Natura de enfrentar a crise provocada pelo uso de uma espécie vegetal ameaçada de extinção na embalagem de seus produtos trouxe conseqüências positivas em todos os níveis:

- A consumidora Ilka Fioravante Altoé e sua família, que haviam parado de comprar e usar os produtos da Natura, voltaram a utilizá-los.

- Todos os colaboradores da empresa conheceram a história dos estojos de imbuia e adquiriram a percepção de que a empresa se esforça para colocar em prática suas crenças e valores, além de reiterar seu compromisso com a responsabilidade social corporativa.

- No exercício da gestão ambiental da Natura, o caso criou um precedente que, desde o início, se tornou referência para ações futuras. Implementada antes da denúncia da consumidora, a Certificação de Ativos, que verifica os planos de manejo na extração de insumos de acordo com critérios de sustentabilidade, passou a receber atenção redobrada. Para uma empresa que se relaciona com fornecedores a enormes distâncias, o rigor na vigilância será, cada vez mais, uma exigência.
- Hoje, no Espaç̧o Natura, colaboradores, fornecedores e visitantes podem ver, ao longo do Rio Juqueri, que corta a reserva verde das instalações da empresa, as mudas de imbuia plantadas ao largo da mata ciliar.

- A bióloga Ilka Fioravante Altoé, que trabalhava como responsável pelo Laboratório de Resíduo Agrotóxico do Instituto Mineiro de Agropecuária, foi promovida a Gerente da Unidade de Garantia da Qualidade, no Laboratório. Além da competência técnica, sua participação ativa como consumidora e defensora do meio ambiente contribuiu para a decisão de seus superiores.

- Os R\$ 65 mil obtidos com as vendas dos estojos de imbuia foram destinados aos projetos de conservação e educação ambiental de uma ONG e de um instituto de pesquisa, eleitos e auditorados pelo Comitê de Meio Ambiente da Natura. 